\title{
A Payment Culture Framework for Municipal Services in the North West Province
}

\author{
Prince Chukwuneme Enwereji ${ }^{1} \&$ Marius Portgeiter ${ }^{1}$ \\ ${ }^{1}$ Department of Management Science, Faculty of Economics and Management Science, North-West University, \\ South Africa \\ Correspondence: Prince Chukwuneme Enwereji, Department of Management Science, Faculty of Economics and \\ Management Science, North-West University, South Africa.
}

Received: March 7, 2020

Accepted: May 20, 2020

Online Published: September 3, 2020

doi:10.5430/rwe.v11n5p56

URL: https://doi.org/10.5430/rwe.v11n5p56

\begin{abstract}
Payment for municipal services in South Africa, especially in the North West province, has been a contentious issue as consumer debt keeps on escalating despite the managerial measures taken by municipal role-players to stop debt accruals. The purpose of this study was to identify the factors that could enhance payment compliance for municipal services, as well as to propose a payment culture framework for municipal services. Residents living within the municipal areas in the four district municipalities of the North West province, municipal role-players, councilors, as well as traditional leaders were involved in this study. Data were collected using a structured questionnaire and were analysed using SPSS. Findings obtained from the study indicate vast opportunities for municipalities to strategically enhance payment compliance. It was discovered that fiscal exchange is the most influential factor to induce residents' inclination to pay for municipal services. Other factors identified to influence payment compliance include deterrence messages, social influence, payment education, budget transparency, service administration, traditional leadership, communication dynamics and adoption of emerging innovation options. Findings also indicate a lack of collaboration between municipal role-players and politicians resulting in administrative versus political dichotomy. The study recommended that municipalities should provide adequate services to residents and initiate payment enforcement measures, communication dynamics, emerging sustaining innovation options, effective collaborations, as well as encouraging traditional leadership to facilitate payment compliance for municipal services in the North West province.
\end{abstract}

Keywords: traditional leadership, communication dynamics, sustaining innovation, collaboration, municipalities, payment culture

\section{Introduction}

The culture of non-payment and payment default for municipal services in South African municipalities has been a contested issue as consumer debt keeps on increasing without adequate administrative measures to halt the escalating accrual. The debt accrual has consequently led to poor service provision resulting in riotous protests and often culminating in vandalising of municipal, private and public properties. Manyaka (2014) pinpoints that escalating consumer debt in the payment for municipal services is among the major challenges facing most municipalities as it has serious implications on their cash flows. In order to achieve adequate service provision in local municipalities, different strategies need to be in place to improve debt management competencies that can enhance payment culture. The South African National Treasury (2012) further affirm that revenue management is an integral function in organisations, including municipalities, as it augments revenue collection and debt management.

The payment for municipal services in the North West province has deteriorated to such an extent that the consumer debt amounts to R117 billion and this has a multiplier effect in the provision of services to residents. Despite the legal frameworks guiding the payment for municipal services, Thiga and Muturi (2015) and Jemaiyo and Mutai (2016) affirm that local municipalities in South Africa neither provide adequate municipal services to residents nor mobilise payments for services provided. Mobilizing adequate revenue need to be prioritised as noted by Manyaka (2014) in order to be financially stable to provide adequate municipal services to residents as constitutionally mandated. Due to the intensifying consumer debts in the local municipalities of the North West province, it was deemed necessary to investigate the payment culture of residents, the factors that could influence the payment culture 
for municipal services, the best management practice to enhance payment compliance and to propose a management framework to establish a responsible payment culture.

After reviewing vast literature, factors such as policies and legislation, social influence, deterrence, fiscal exchange, payment knowledge and understanding, budget transparency, and service administration were identified by Fjeldstad \& Heggstad (2012), USAID (2013), Luttmer \& Singhal (2014), Thiga and Muturi (2015), USAID (2016), and Mascagni, Nell \& Monkam (2017) as the factors that could influence the payment for municipal services. This study added traditional leadership, communication dynamics, and emerging sustaining innovation options as factors that could also influence the payment culture for municipal services. Consequently, the study noted that the concepts of strategic management as a management practice could be employed by the municipal role-players to enhance the payment culture of residents. All these factors were tested in the empirical investigation of this study to know if they do influence the payment culture for municipal services.

The subsequent section briefly expounds on the concept of strategic management

\section{Strategic Management}

Strategic management refers to the nature of actions or activities that are taken by managers to ensure that the performance of an organisation will equal or ideally exceed expected targets (Parnell, 2014). The failure and/or success of organisations depend on management's strength in implementing strategies aimed at achieving strategic advantage and/or growth. Hill et al. (2017) allude that a strategic leader should be capable of managing the affairs of an organisation, especially in the decision-making process to convert input into output. Strategic management includes all measures involved in the implementation of strategies into reasonable action, such as designing products and/or services and supporting the lifeline of such products or services. Strategic management enables an organisation to improve its efficiency in discharging its operations through the ability of strategic leaders to specify authority; design organisational structure which provides guidance on human resource functions and decision making; control systems; and cultivating a responsible organisational culture (Stewart et al, 2017).

Ungerer et al. (2015) ascertain that strategic management is a discipline that deals with an organisation's policy formulation which is informed by the planning and programme development that have long-term future prospects. In line with the above, strategy refers to the way leaders think or act in the implementation of the long term vision of an organization (a municipality in this case). Partidario (2012) asserts that the concept of strategic management entails assessing the internal and external elements of the business environment to understand the variables that contribute to the attainment of organisational goals and making flexible decisions to achieve efficiency. Strategic management also involves the assessment of opportunities and risks involved in driving sustainable development, incorporating social, institutional and economic circumstances, and also facilitating stakeholder engagement through a collaborative process (Partidario, 2012).

Bruton and White (2011) affirm that strategy is the totality of actions that help achieve organisational objectives. Strategic management entails the procedures where the type of business that an organisation wishes to adopt and the type of human and financial resource needed to achieve the proposed business plans are outlined and communicated (Lynch, 2015). It is under strategic management practice that an organisation (municipality) makes its policies and plans to ensure that all efforts are directed towards achieving pre-stated objectives. Strategic management builds the foundation and direction to achieve several organisational activities over forthcoming years. Strategic management directly benefits an organisation as it builds a basis through which the organisation moves towards consistency in achieving its objectives (Bruton \& White, 2011).

Amason (2011) strongly contends that the concept of strategic management involves an investigative process. An investigative process refers to choosing an integrated course of action and reasonably mapping out measures to execute actions. Strategic management enables an organisation to make continuous improvement by doing what is right at the appropriate time. Katsioloudes and Abouhanian (2017) pinpoint that strategic management provides a background for management to source more cost-effective means so that the organisation can initiate change, achieve change or adapt to change. In a situation where an organisation does not perform excellently, Meyer (2012) opines that strategic leaders are then the key solution in providing direction to obtain its competitiveness within its business environment. Strategic management also provides a blueprint of where an organisation wants to be in the nearby future and it also indicates how an organisation is to achieve its objectives (Gamble et al., 2017).

Municipal employees (in this case) could employ the practice of strategic management to ensure that a payment culture for municipal services could be enhanced to halt the escalating consumer debts in the North West provincial municipalities, as well as stop the incessant service provision protests and increase consumer satisfaction. 


\section{Research Methodology}

This study adopted a positivist paradigm which believes that reality is fixed, measurable and knowable (Creswell, 2014). This facilitated the adoption of the quantitative approach that enabled the researcher to find relationships existing among interacting variables, as well as discovering a path to create an acceptable framework to enhance a payment culture for municipal services in the North West province. The population sets were drawn from the four district municipalities of the North West province to include 285251 residents in the municipal areas that receive municipal services.

Residents of the local municipalities were selected using convenience sampling. The sample sizes for the municipalities were further compounded using Research Advisor's (2006) sample size calculator by following a 95\% confidence interval and 5\% degree of accuracy/margin of error. According to the sample size calculator, the sample size for the residents is 384 . The sample frame is further computed by using proportional sampling strategy based on the sample fraction. The reason for this was to obtain the exact number of sample members that were drawn from each municipality.

$$
\text { Sample fraction }=\frac{\mathrm{n}}{\mathrm{N}}=\frac{384}{285251} \quad 0.0013461828
$$

Sample frame $=$ population $\times$ sample fraction $($ see Table 1 below $)$

Table 1. Sample size for residents receiving municipal services

\begin{tabular}{lcc}
\hline Municipality & $\begin{array}{l}\text { Total no. of } \\
\text { residents }\end{array}$ & Sample frame \\
\hline Mahikeng & 103333 & 139 \\
\hline Moses Kotane & 80654 & 109 \\
\hline JB Marks & 80572 & 108 \\
\hline Naledi & 20692 & 28 \\
\hline Total & $\mathbf{2 8 5 2 5 1}$ & $\mathbf{3 8 4}$ \\
\hline
\end{tabular}

Data was collected using self-administered questionnaires and was analysed using Statistical Package for Social Sciences (SPSS) software version 24.

\section{Results}

In the presentation phase, the descriptive and the inferential statistics were presented followed by the final framework of the study.

\section{(1) Biographical information of the respondents}

Concerning the gender of the respondents, more respondents were females (54\%) than males who accounted for $46 \%$ in the study. The study revealed that more household owners (23.4\%) who participated in this study were between 46 and 55 years. This was followed by respondents who were within the age range of 56-65 (22.6\%), 26-35 (20\%) years, and 36-45 (19\%) years. Respondents within the age limit of 21 or less (14\%) and 66 and above (3\%) were the minority in this study. Of interest to note is that those who participated in this survey were between 26 to 65 years of age (83.1\%). With regard to the respondents' academic background, it is observed that more respondents have matric (30.6\%) as their highest qualification. This was followed by respondents with a Bachelor's degree (21.2\%), of diploma (13.6\%) and an Honours degree (13.6\%). Respondents with Master's or a $\mathrm{PhD}$ degree $(7 \%)$ are the minority groups of respondents. More of the respondents in this study reside in Mahikeng local municipality (33.7\%) than other municipalities. This was followed by Tlokwe (28.1\%), Moses Kotane $(27.3 \%)$ and Naledi (10.6\%) respectively. The study also noted that the majority of the respondents have lived for more than 21 years (47.6\%) in their municipalities. The respondents are thus regarded as knowledgeable about their local municipalities and qualified to respond to the questions included in the research instrument.

The study discovered that (50.2\%) of the residents pay their municipal bills consistently. It is alarming that $49.8 \%$ of the respondents are defaulters in the payment for municipal services. These residents directly form part of those causing high consumer debt crisis in the North West province. About their monthly income, $81 \%$ of respondents earn from R10 000 to R21 000. Also, 19\% of the residents earn below R10 000 indicating that more respondents are 
capable of paying their municipal services and as such, are not considered as indigent residents. With regard to the billing, more residents (51.8\%) indicate that they are billed between R501 and R1000 monthly for services rendered. This indicates that the municipal services are fairly affordable when compared to the monthly income responses of the respondents where most respondents indicate that they earn from R15 100-R21 000 per month and therefore afford always and/or frequently to pay their municipal bills. Further investigation confirms that politicians, municipal manager, politicians and village chiefs are recognised as role-players in the municipalities. Others who made a small percentage are religious leaders and traditional title holders. However, the respondents confirmed that the most important role-players are politicians (43\%). This depicts that politicians and municipal managers are identified as dignitaries who could make a substantial contribution towards creating a payment culture and turn around the intensifying municipal debt. Views on connectivity are compounded in Table 2.

Table 2. General views on connectivity

\begin{tabular}{lll}
\hline Views measured & Yes $\mathbf{( \% )}$ & No $(\%)$ \\
\hline Mobile phone & 90 & 10 \\
\hline Email & 88 & 12 \\
\hline Mobile phone with Internet & 83 & 17 \\
\hline Access to nearby ATM & 75 & 25 \\
\hline Access to social media account & 71 & 29 \\
\hline Private postal mail box & 54 & 46 \\
\hline Desktops with internet & 46 & 54 \\
\hline
\end{tabular}

Table 2 depicts that most respondents have access to mobile phones, emails contacts, mobile phones with the Internet, access to nearby ATM, access to social media account and access to postal mail box. Only a few respondents indicated that they don't have access to desktops with the internet. This section concludes that all the items listed in Table1 (except desktops with internet) could be adopted by the municipalities to communicate with the residents, as well as collect payments from the residents.

\section{Reliability of data collecting instruments}

The Cronbach's alpha coefficients in Table 3 are more than 0.7 or close to 1 thus suggesting that all the constructs measured have relatively high internal consistency.

Table 3. Reliability analysis

\begin{tabular}{lcc}
\hline CONSTRUCT & Cronbach's Alpha & No. of Items \\
\hline Legislation & 0.866 & 12 \\
\hline Social Influence & 0.86 & 5 \\
\hline Deterrence & 0.836 & 6 \\
\hline Fiscal Exchange & 0.811 & 10 \\
\hline Payment Education/Awareness & 0.784 & 6 \\
\hline Budget Transparency & 0.899 & 7 \\
\hline Service Administration & 0.849 & 12 \\
\hline Traditional Leadership/ Councillors & 0.953 &
\end{tabular}

\section{Relationship between payment behaviour and independent variables}

A Chi-square test of independence was computed to investigate the relationship existing between payment behaviour and independent variables such as legalisation, social influence, deterrence, fiscal exchange, payment education/awareness, budget transparency, traditional leadership, communication dynamics, and sustaining innovation. All p-values obtained from the statistical results in Table 4 are less than the 0.05 level of significance 
(p-value <0.05) and the closest being 0.042 for budget transparency. This implies that there is a significant association between payment behaviour and legislation, service administration, payment education/awareness, deterrence, budget transparency, fiscal exchange, social influence, traditional leadership, innovation and improved communication and the payment culture for municipal services. Positive correlations imply that residents who have been paying rates for a long time tend to agree with the listed items and vice versa.

Table 4. Payment behaviour and independent variables

\begin{tabular}{lllcc}
\hline Association between payment culture and: & Statistics & Value & df & $\begin{array}{c}\text { Asymptotic } \\
\text { Significance } \\
\text { (2-sided) }\end{array}$ \\
\hline Legislation & Likelihood Ratio & $27.642^{* *}$ & 9 & 0.001 \\
\hline Social influence & Likelihood Ratio & $18.032^{* *}$ & 9 & 0.031 \\
\hline Deterrence & Likelihood Ratio & $38.074^{* *}$ & 9 & 0.002 \\
\hline Fiscal exchange & Likelihood Ratio & $50.024^{* *}$ & 9 & 0.000 \\
\hline Payment education/ awareness & Pearson Chi-Square & $29.042^{* *}$ & 9 & 0.012 \\
\hline Budget transparency & Likelihood Ratio & $17.464^{*}$ & 9 & 0.042 \\
\hline Service administration & Pearson Chi-Square & $18.59^{*}$ & 9 & 0.030 \\
\hline Traditional leadership & Pearson Chi-Square & $28.077^{* *}$ & 9 & 0.001 \\
\hline Communication dynamics & Pearson Chi-Square & $24.055^{* *}$ & 9 & 0.001 \\
\hline Emerging sustaining innovation & Pearson Chi-Square & $21.033^{* *}$ & 9 & 0.011 \\
\hline & & & &
\end{tabular}

\section{One-way ANOVA}

In this study, the Kruskal-Wallis $\mathrm{H}$ test was applied for both continuous and ordinal-level dependent variables. The Kruskal-Wallis H test (also called the 'one-way ANOVA on ranks') is a rank-based nonparametric test used to determine if there are statistically significant differences between two or more groups of an independent variable on a continuous or ordinal dependent variable. This test was conducted to understand the responses of the respondents on each construct in each selected local municipality. Table 5 presents the results of Kruskal-Wallis $\mathrm{H}$ test on all the constructs.

Table 5. Kruskal-Wallis H test

\section{TEST STATISTICS}

\begin{tabular}{lllllllllll}
\hline & & & & & & \\
\end{tabular}

Table 5 shows that the responses on legislation, social influence, deterrence, service administration, traditional 
leadership and payment behaviour differ significantly across the municipalities (p-values $<0.05$ ). Responses to all the other factors in the table above do not differ significantly across the municipalities (p-values $>0.05$ ). The responses to the factors with significant differences presented are further dealt with below.

\section{Kruskal Wallis $\mathbf{H}$ test on Legislation}

The Kruskal Wallis $\mathrm{H}$ test was applied to investigate how the respondents reacted to the variables used to measure legislation in all the four local municipalities investigated and their responses are presented in Figure 1. An attempt was made to present the positive responses (agree, strongly agree) and negative responses (disagree, strongly disagree) to provide a comprehensive view of the responses.

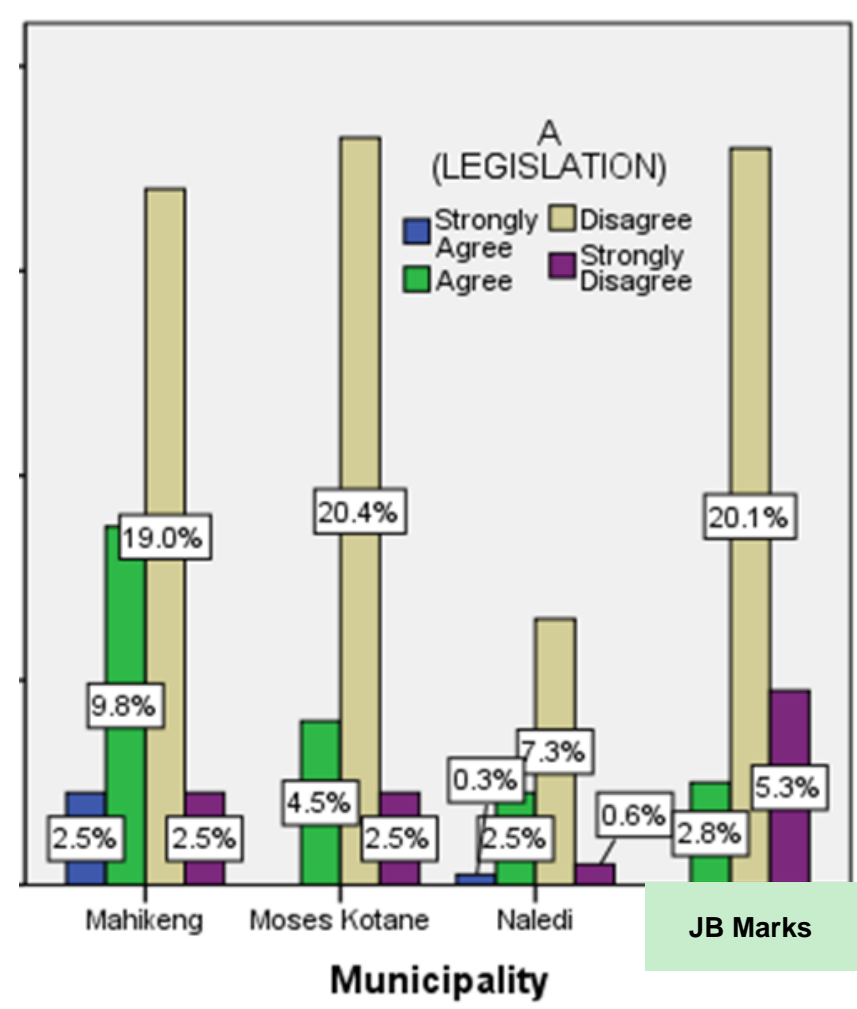

Figure 1. ANOVA test on legislation

Note: All the percentages of all variances total $100 \%$

As indicated in Figure 1, the inclination of the responses show that more respondents from Mahikeng municipality are positively inclined (12.3\%) towards the variables used to measure legislation than any other of the municipalities. Furthermore, it is observed that more respondents from the JB Marks local municipality are negatively inclined $(25.6 \%)$ to the variables used to measure legislation. Comparing the results obtained in JB Marks with those from Mahikeng Municipality, there is a difference of (13.3\%) indicating that municipal role-players in the Mahikeng local municipality do educate residents on the content of legislation guiding the payment for municipal services more than JB Marks municipality. However, it could be concluded that the content of South African legislation could be used to enhance the payment culture of residents.

Kruskal Wallis H test on Social Influence

The Kruskal Wallis H test was conducted to determine if there is any disparity amongst the respondents in terms of social influence in the four local municipalities and the results are presented in Figure 2. The findings in Figure 5.32 indicate that more respondents in the Mahikeng local municipality (27.1\%) and Moses Kotane (26.5) are positively inclined to the variables used to measure social influence than any other municipality. However, respondents in the Mahikeng local municipality (6.7\%) and JB Marks local municipality (3.1\%) tend to be negatively inclined to variables used to measure social influence. The finding in this section indicates that residents in Mahikeng and 
Moses Kotane local municipalities socially interact in their neighbourhood more than any other municipality. Also, it could be deduced that residents in Mahikeng and JB Marks do not believe in political discouragement and other variables used to measure social influence. The results obtained shows that social influence could be used to facilitate payment culture of residents.

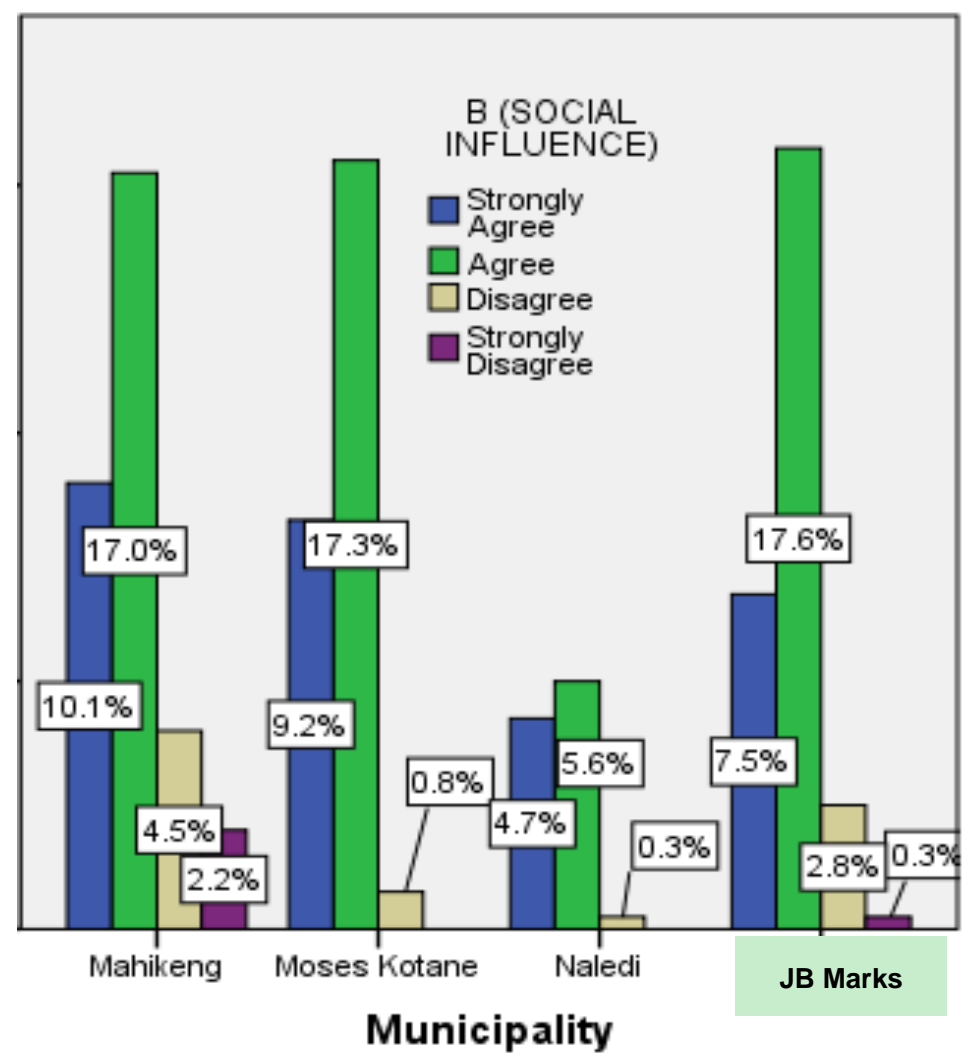

Figure 2. ANOVA test on social influence

\section{Kruskal Wallis H test on deterrence}

Kruskal Wallis H test was used to determine respondents' responses on deterrence in the four local municipalities and the results are presented in Figure 3. More respondents from JB Marks (26.8\%) and Moses Kotane (26.5\%) local municipalities are positively inclined to the variables used to measure deterrence. Also, more respondents from Mahikeng (8.6\%) are negatively inclined to all the variables used to measure deterrence. The findings in this section indicate that the objects of deterrence are applied by the municipal role-players in JB Marks and Moses Kotane municipalities more than the role-players in Mahikeng local municipality and Naledi. Due to the level of agreement to the factors used to measure deterrence by residents of JB Marks and Moses Kotane, the application of deterrence concept could yield effective results in these municipalities, specifically in persuading residents to adopt a culture of paying for municipal services rendered. 


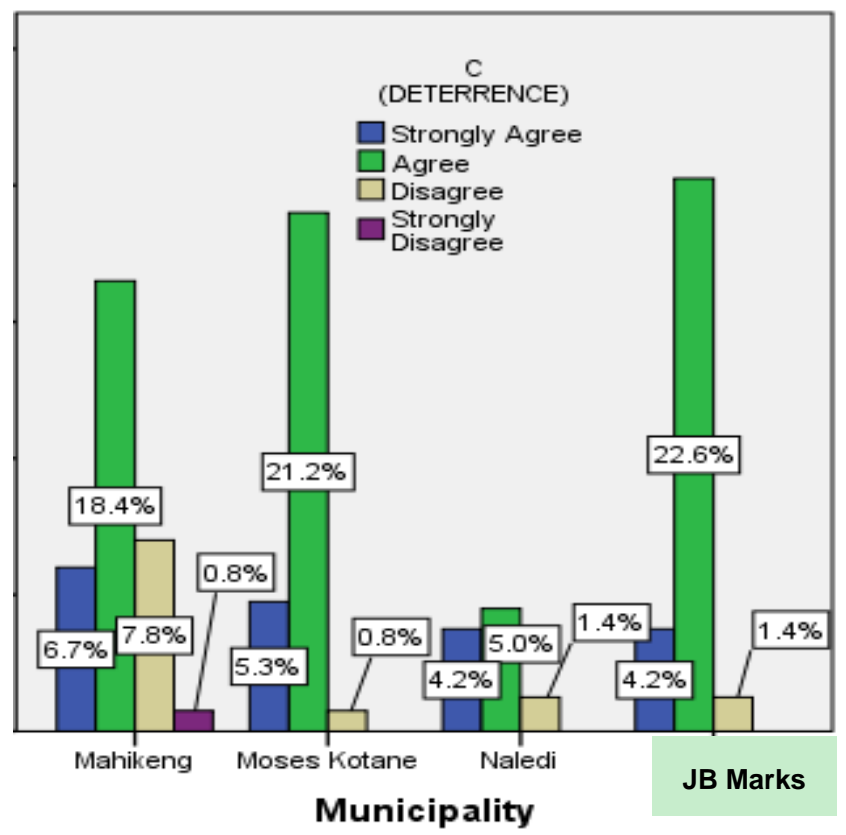

Figure 3. ANOVA test on deterrence

\section{Kruskal Wallis $\mathbf{H}$ test on service administration}

Kruskal Wallis $\mathrm{H}$ test was conducted to understand the degree of agreement of respondents' responses on service administration in the four local municipalities and their responses are presented in Figure 4. More respondents from Mahikeng (15.1\%) and Moses Kotane (12.0\%) municipalities are positively inclined to all the variables used to measure service administration whereas more respondents from JB Marks $(20.1 \%)$ are negatively inclined on the variables used to measure service administration. The agreement by the respondents indicates that the municipal role-players in Mahikeng and Moses Kotane do facilitate voluntary payment compliance in these municipalities; hence more effort is required in JB Marks and Naledi to facilitate voluntary payment compliance. Above all, results show that deterrence could be employed by municipal workers to enhance payment culture of residents.

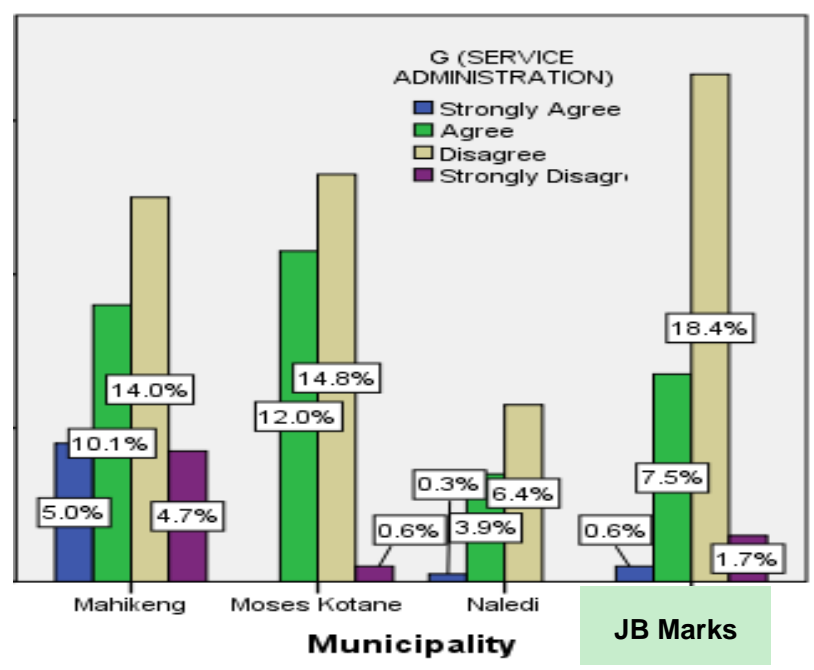

Figure 4. ANOVA test on service administration

Note: All the percentages of all variances total $100 \%$ 


\section{Kruskal Wallis $\mathbf{H}$ test on traditional leadership}

Kruskal Wallis $\mathrm{H}$ test was computed to understand the disparity of responses from respondents on traditional leadership in the four local municipalities and the results are presented in Figure 5. Results depict that more respondents from Moses Kotane (25.1\%) and JB Marks (21.5\%) are positively inclined to the variables used to measure traditional leadership in the study whereas more residents in Mahikeng (18.2\%) are negatively inclined to the variables used in measuring the impact of traditional leadership. The findings in this section indicate that traditional leadership is likely to be more successful in Moses Kotane and JB Marks local municipalities than any other municipality measured. Traditional leadership should be encouraged in Mahikeng and Naledi respectively in an endeavour to enhance a responsible payment culture. The results obtained in this category depict that engaging traditional leaders in the management of service provision could assist in enhancing the payment culture of residents.

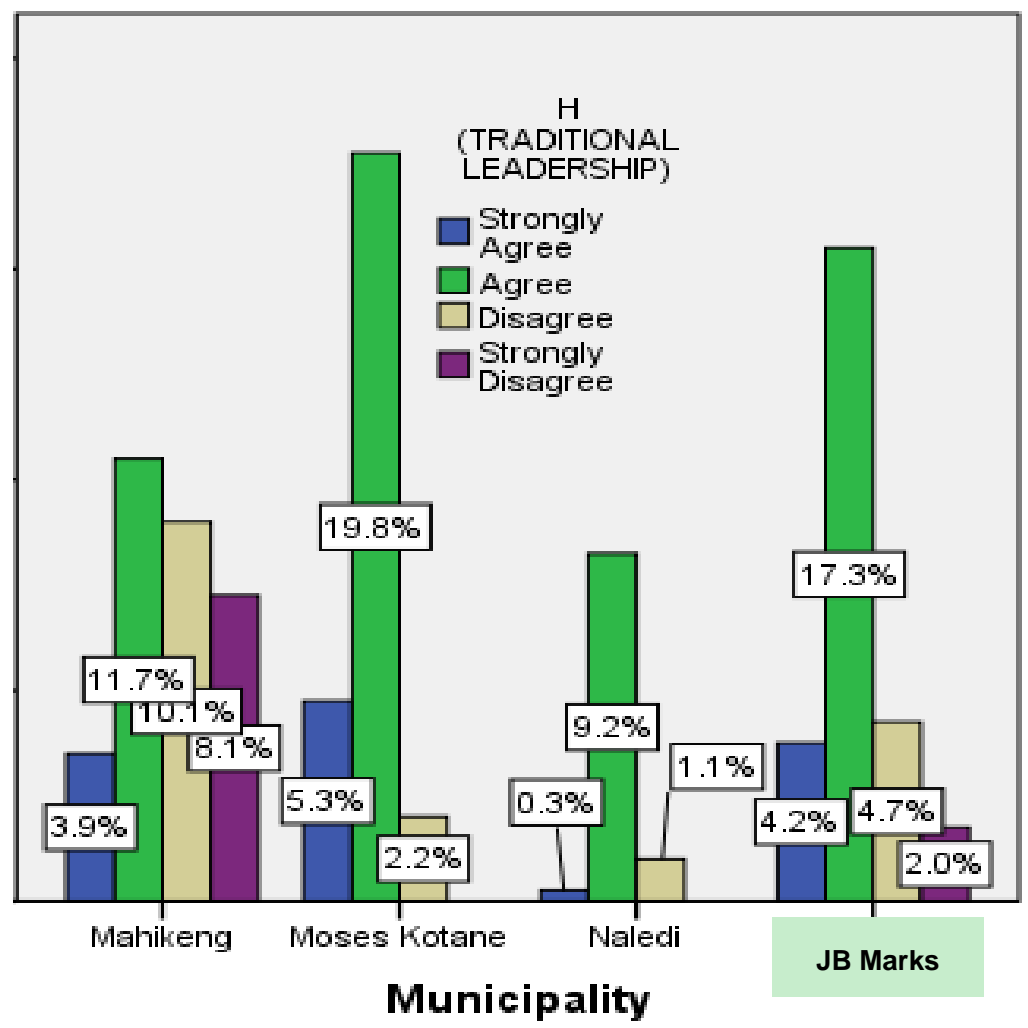

Figure 5. ANOVA test on traditional leadership

\section{Kruskal Wallis $\mathbf{H}$ test on payment behaviour}

Kruskal Wallis $\mathrm{H}$ test was applied to investigate how the respondents react to the variables used to measure payment behaviour in the four local municipalities and their responses were presented in Figure 6. The responses obtained in Figure 6 portrays that more respondents from JB Marks (21\%), Mahikeng (20.9\%) and Moses Kotane (20.9) are positively inclined to the payment for municipal services constituting almost $63 \%$ of the total payment compliance. Also, more residents in Mafikeng (12.8\%) are negatively inclined to voluntary payment compliance, others such as JB Marks (7.3\%), Moses Kotane (6.4\%), and Naledi (3.1\%) are involved in payment default for municipal services constituting to $29.6 \%$ default. This findings obtained in this section indicates that municipal role-players should facilitate voluntary compliance in all the local municipalities through collaboration, payment enforcement, communication, traditional leadership, emerging innovation and equitable service provision to enhance payment compliance. 


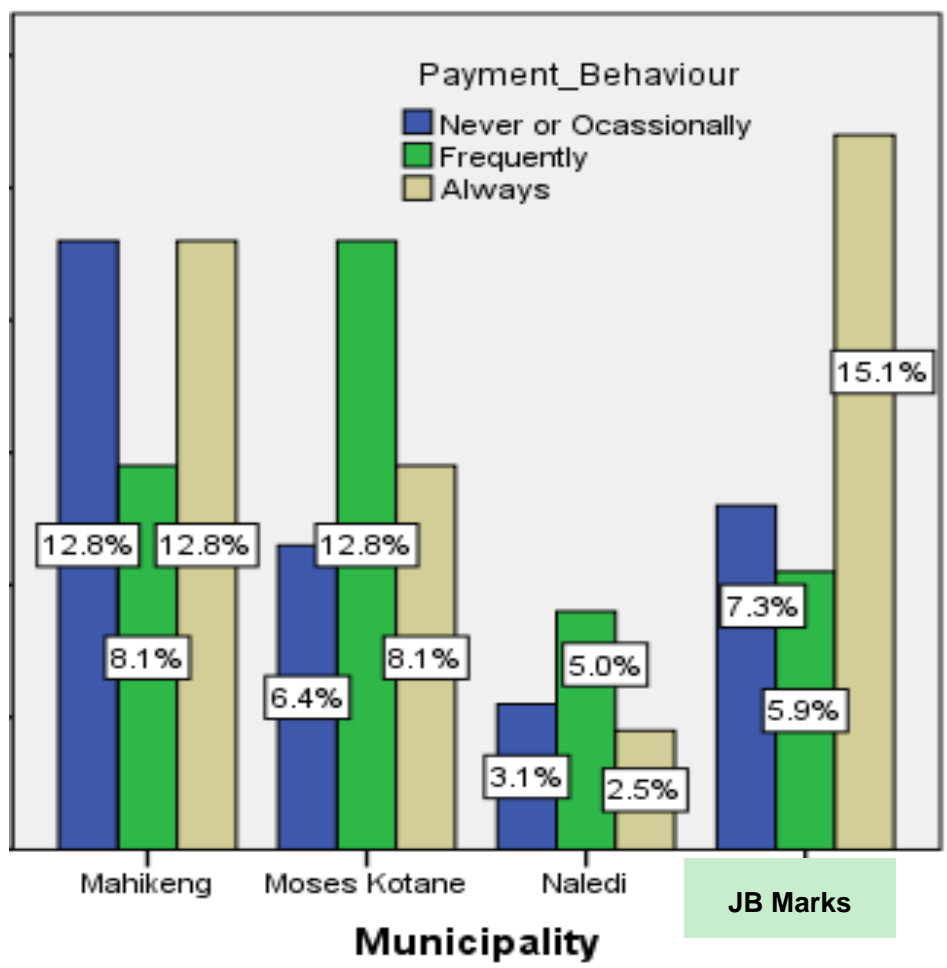

Figure 6. ANOVA test on payment behaviour

\section{Structural Equation Model (SEM) for payment culture}

This statistical test was conducted to examine the association between payment behaviour and legislation, social influence, deterrence, fiscal exchange, payment education, budget transparency, service administration, and traditional leadership. The following Structural Equation Model (SEM) was developed based on the statistical relationships between the respective variables. The first output evaluates the fit of the model and Table 6 presents the fit summary analysis.

Table 6. Fit summary analysis

\begin{tabular}{ll}
\hline & FIT SUMMARY \\
\hline Standardized RMR (SRMR) & 0.0597 \\
\hline Goodness of Fit Index (GFI) & 0.9674 \\
\hline RMSEA Estimate & 0.0658 \\
\hline Comparative Fit Index (CFI) & 0.8608 \\
\hline
\end{tabular}

The following Structural Equation Model (SEM) was developed based on the statistical relationships between the respective variables. The first output evaluates the fit of the model. The fit indices are interpreted based on the benchmarks recommended by Van de Schoot et al. (2012) and Hooper et al. (2008). All relationships are statistically significant at $1 \%$ or $5 \%$, and are all positive. The strength of the correlations may be interpreted as follows: $r=0$ implies that there is no correlation, $0<r<0.3$ indicate a weak correlation, $0.3 \leq r<0.5$ shows moderate correlation and $r \geq 0.5$ indicate a strong correlation (Weinberg \& Abramowitz, 2016). The results show that the CFI (Comparative Fit Index) is greater than the recommended lower benchmark of 0.95, and the GFI is close to the recommended benchmark of 0.9 , therefore indicating that the model fits the data reasonably well. Also, the RMSEA (Root Mean Square Error of Approximation), as well as the SRMR (Standardized Root Mean Residual) are less than the upper cut-off point of 0.08 which also indicate that the model fits the data well. Figure 7 presents the quantitative fit model. 


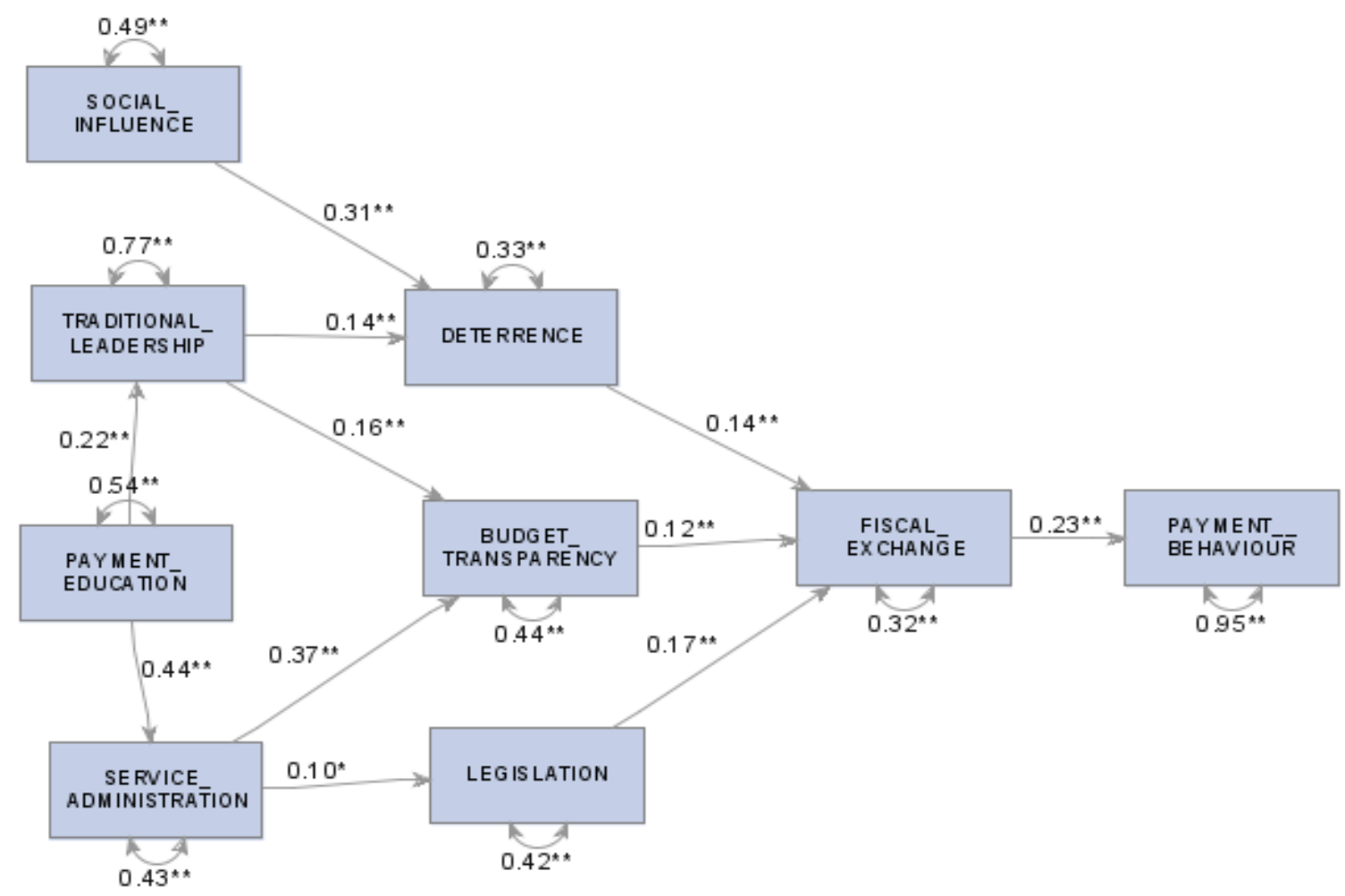

Figure 7. Quantitative fit model

The SEM shows that only fiscal exchange has a direct and positive relationship with a person's payment behaviour. Other variables do not have a direct relationship with the dependent variable but are related to it through other independent variables. All the variables measured are positively related to payment behaviour which depicts that these items could be utilised to influence payment culture for municipal services.

\section{Payment Culture Framework}

Payment culture, as indicated in the introduction of this study, refers to an acceptable way of payment in a given geographical location. The study of Bird (2015) affirms that South Africa, especially the North West province, has been battling for saveral number of years with the development of a sound payment culture for municipal services. As indicated in the introduction, a payment culture framework is proposed in this study to the municipal role-players and other policy makers to enhance a reputable payment culture for municipal services as the end goal of this study. The payment culture framework as presented in Figure 8 incorporates the empirical findings from the quantitative dataset. 


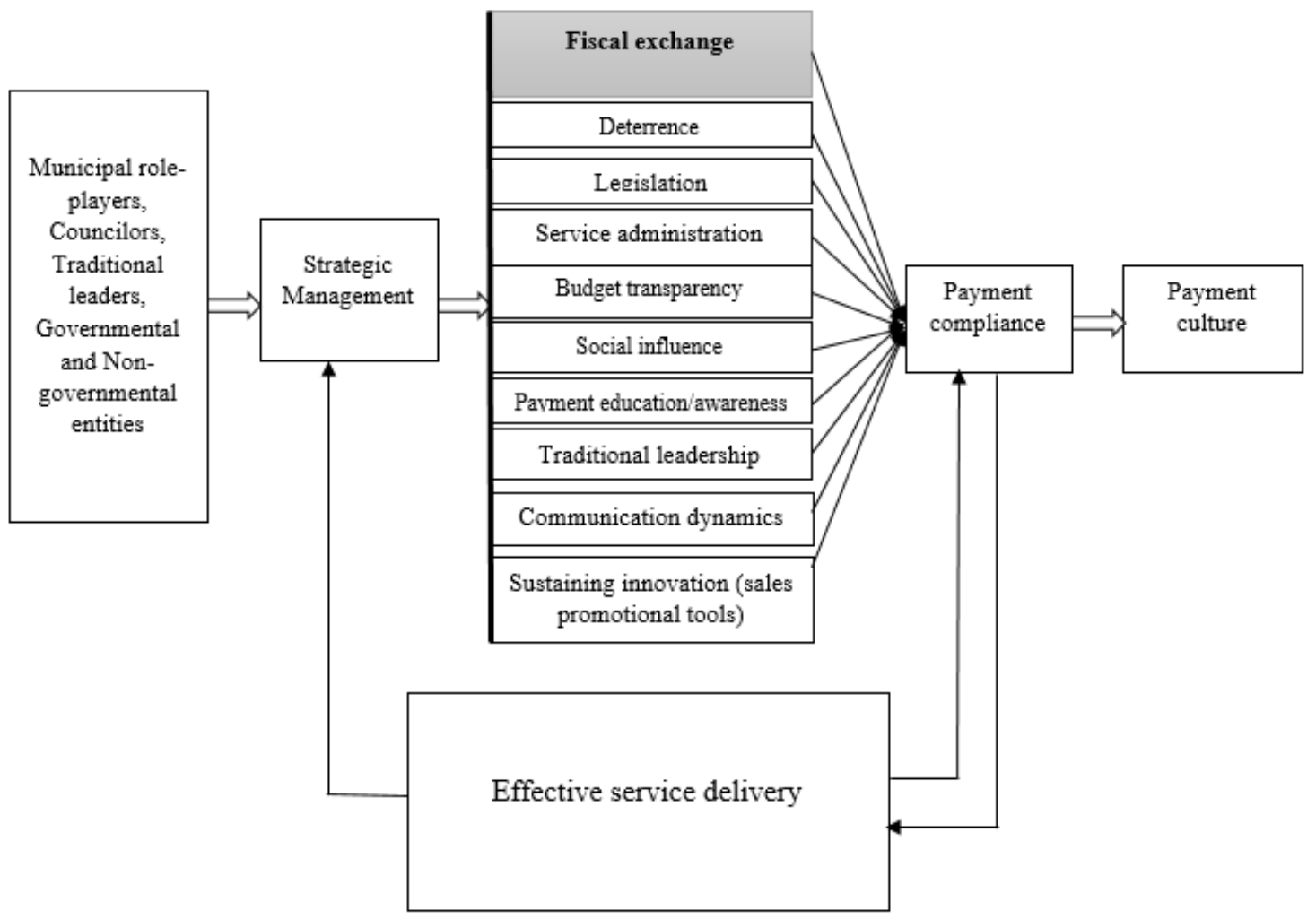

Figure 8. Payment culture framework for municipal services

The payment culture framework presented in Figure 8 is the main contribution of this study which indicates that there should be a collaboration between municipal role-players, councillors, traditional leaders, governmental and non-governmental entities in an endeavour to achieve a payment culture for municipal services. The framework further portrays that these persons, agents and entities should adopt the prescripts of strategic management to manage the factors identified as influencing payment compliance: fiscal exchange, policy and legislation, social influence, deterrence, payment education/awareness, budget transparency, service administration, traditional leadership, communication dynamics and sustaining innovation to achieve payment compliance. However, it was discovered in the empirical studies that fiscal exchange is the main factor that could be applied by the role-players to achieve effective payment compliance. In combination, the application of all these factors is anticipated to finally enhance a responsible payment culture.

The framework shows that payment compliance induces service delivery indicating that when residents pay their municipal services equitably then municipal role-players deliver services effectively. Consistent with this, the framework further depicts that effective service delivery could invariably motivate residents to pay for their municipal services. Finally, the framework portrays that management should always refer to the prescripts of strategic management in order to revisit their transformational approaches due to change in the internal and external environments in an endeavour to stabilise a responsible payment culture for municipal services.

\section{Recommendations}

This study makes recommendations to municipal role-players, councillors, traditional leaders, residents and policy makers.

\subsection{Recommendation to Municipal Role-Players}

The following recommendations are made to municipal role-players:

- Municipalities should endeavour to provide adequate municipal services to residents.

- In the service provision obligation, the health and education sector should be given reasonable consideration.

- Municipal role-players should obtain the commitment of residents by giving them agreement forms related to 
the payment for municipal services to sign in order to be legally binding in a contractual relationship to pay for their municipal services.

- There should be a concrete agreement between the municipality and residents on how the municipal services should be increased or an explanation of how surcharges are added.

- Municipalities should include deterrence messages to influence residents to pay their bills.

- Appeals to pay debts should be made consistently to residents to induce compliance.

- Municipal role-players should collaborate effectively with residents; IDP meetings should be scheduled at regular intervals throughout the year and should not be only an annual event.

- Municipal role-players should collaborate in mutually with councillors to educate and mobilise payments from residents.

- Indigent records should be updated by municipalities to identify residents who should be added as indigent.

- The level of governance should be upgraded with regard to uniformed service provision, billing and payment enforcement.

- Municipal role-players should consistently educate residents on matters related to payment.

- Municipal budgets should be communicated to residents; also, residents should be allowed to make contributions during the budget process.

- In order to project a clean image, role-players should disseminate municipal budgets at regular intervals in order to dismiss the suspicion of looting of public funds.

- The registration of residents, evaluation and monitoring of accounts, auditing and customer care should be implemented effectively to induce voluntary compliance.

- Municipal role-players should collaborate with traditional leaders and councillors to ensure that residents are engaged in enhancing a responsible payment culture.

- Apart from using television and radio advertisements to reach residents, municipal role-players should adopt other measures such as YouTube, billboards, fliers, Internet, social media, reminders by SMS and email, inserts in newspapers, newspapers, and drama in theatre to create awareness for the payment of service provision.

- In sending bills, municipal role-players should also consider email addresses and mobile phones as almost all residents in the study indicated that they own such gadgets and facilities.

- Other means of payment, such as EFT, ATM payments, debit and stop orders, should be encouraged to ease queuing stress at municipal offices.

- Municipal role-players should introduce promotional tools such as coupons, premiums, displays, samples, consumer sweepstakes, shop orders and patronage rewards to induce residents to pay for their municipal services.

\subsection{Recommendations to Councillors}

The following recommendations are made to councillors:

- Politicians should not make empty promises to the residents so that residents do not act on false promises.

- Councillors should collaborate with municipal role-players to ensure that the payment culture is enhanced.

- All complaints received from residents should be reported to the municipality immediately.

- Councillors should motivate residents to pay for their municipal services rather than making derogatory statements about municipal employees.

- Indigent records should be compiled by councillors representing each ward so that municipalities know who should be considered indigent.

- Change of title deeds should be initiated by residents so that properties bear the names of the owners.

- Councillors should collaborate with traditional leaders, village chiefs, SANCO, governmental and non-governmental organisations to ensure that a responsible payment culture is inculcated.

\subsection{Recommendations to the Traditional Leaders}

The following recommendations are made to traditional leaders: 
- Residents should be equitably engaged to understand the impact of their dereliction of payment for their municipal services.

- Traditional leaders should engage residents at regular intervals and encourage them to pay for services and to highlight the programmes and new policy dimensions of the municipality.

- Traditional leaders should collaborate effectively with municipal role-players to ensure that they enhance a responsible payment culture.

\subsection{Recommendations to Residents}

The following recommendations are made to residents:

- Residents should attend annual IDP meetings and contribute towards the decision-making process and policy amendments to ensure that they are part of the council.

- Residents should report favouritism in municipal service provision.

- Residents should accept their obligations in good faith to be law-abiding and to pay for their services rather than be discouraged by external influences.

- Residents should respond to the appeals from municipalities to pay their accrued debts.

- Residents should report dissatisfaction with service delivery to the municipality rather than withhold payment.

- Residents should collaborate with role-players, councillors, traditional leaders and they should also report concerns that could inhibit the payment for services.

\subsection{Recommendations to Policy Makers}

Policy makers should ensure that:

- There is a comprehensive stakeholder audit in the municipality to ensure transparency in the municipal system.

- There is stakeholder engagement which should be aligned to municipal strategy.

- The deployment of municipal employees should be merit-based and not politically induced.

- Municipal implementation of programmes ought to be monitored by existing legislative frameworks.

- Municipalities should uphold transparency and accountability while oversight should be held in high esteem.

- There should be consistent and active results-based monitoring and an evaluation system for municipal role-players with regard to service provision.

- Regular reporting back to local communities is encouraged.

\subsection{Recommendations for Future Research}

This study investigated the factors that could enhance payment compliance for municipal services, as well as proposing a payment culture framework for municipal services. With regard to the findings obtained in this study, it is recommended that another study should examine the managerial capacity of municipalities and the strategies they adopt in collaborating with all the stakeholders in the community. The study further proposes that research on governance and skills impact on municipal service delivery could be conducted in future or a study to understand the capacity of the municipal monitoring team and the customer care service to understand if the municipalities possess the required capacity to mobilise debt to ensure service delivery.

\section{Conclusion}

This study investigated factors that influence payment culture for municipal services in the North West province of South Africa. The factors investigated include fiscal exchange deterrence messages, social influence, payment education, budget transparency, service administration, traditional leadership, communication dynamics, emerging innovation options. This study was motivated by constant riotous protests by residents, poor municipal performance, and a lack of stakeholder engagement between municipalities and residents or other role-players in the communities. The foremost aim of the study was to create a framework that could serve as a guide for municipalities that could be applied in their endeavour to create a responsible payment culture. Furthermore, this study investigated the causes of payment default, non-payment of municipal services and the management practices that municipal role-players could adopt for the administration of their municipalities.

A total of four local municipalities were selected from four district municipalities and were involved in this study. The respondents of this study include residents living in the municipal areas, municipal role-players (municipal 
managers, accountants, ICT manager), councillors and traditional leaders. Findings from the empirical study indicate that policies and legislation, social influence, deterrence, fiscal exchange, payment education/awareness, budget transparency, service administration, adoption of communication dynamics and emerging sustaining innovation influence payment compliance for municipal services, as well as enhancing a reputable payment culture. However, it was deduced that these factors are currently not effectively implemented by municipal role-players and this is reflected in the payment default and non-payment for municipal services by residents.

It was also identified that fiscal exchange is a prime motivator to enhance payment compliance. Residents indicated their utmost dismay towards the nature of service provision by municipalities, thus highlighting how this has an effect on their payment patterns. More so, the study deduced that there is political interference which negatively influence residents to default in the payment for municipal services. This challenge has created superfluous bureaucratic mishaps within the municipal context resulting in an unsavoury contest between administrative and political directives.

Furthermore, the study identified that the prescripts of strategic management are lacking in municipal administration. This is evidenced in the inability of municipal role-players to collaborate effectively with all stakeholders in the community in order to achieve a sustainable payment culture. It was observed that municipalities lack vision and need to improve their managerial competence and strategies in order to achieve their stipulated objectives. There are also technological barriers as municipalities have not adopted communication dynamics and emerging sustaining innovations to communicating with residents and to collect service payment respectively. This and other reasons have plagued achieving a responsible payment culture.

This study established a link between municipal role players and others, strategic management, factors influencing payment compliance, payment compliance, payment culture and effective service delivery. However, to enhance an effective payment culture, municipalities should effectively facilitate the factors affecting payment compliance. This study also highlighted that collaboration amongst all stakeholders is a key to resolving the contradictions between municipal administration and the political cabal. In an endeavour to achieve a required payment culture, this study finally submits that municipalities should ensure equitable service delivery to residents, collaborate with all stakeholders, and deploy payment enforcement measures effectively. This would put to an end to the non-payment culture and payment default identified in this study, as well as the incessant riotous protests for poor service delivery.

\section{References}

Amason, A. (2011). Strategic management: from theory to practice. New York: Taylor and Francis.

Bird, R. M. (2015). Improving tax administration in developing countries. Journal of Tax Administration, 1(1), 23-45.

Bruton, G. D., \& White, M. A. (2011). Strategic management of technology and innovation. New York: Cengage Learning.

Fjeldstad, O. H., \& Heggstad, K. (2012). Local government revenue mobilisation in Anglophone Africa. CMI Working Paper, WP 2012:6 Bergen: Chr. Michelsen Institute.

Gamble, J. E., Peteraf, M. A., \& Thompson, A. A. (2017). Strategic Management: The quest for competitive advantage. New York: McGraw Hill Education.

Hills, C. W. L., Schilling, M. A., \& Jones, G. R. (2017). Strategic management: an integrated approach. Theory and cases. Australia: Cengage Learning.

Hooper, D., Coughlan, J., \& Mullen, M. (2008). Structural equation modelling: Guidelines for determining model fit. Articles, 2.

Jemaiyo, B., \& Mutai, G. C. (2016). Determinants of tax compliance and their influence on the level of tax compliance in the real estate sector, Eldoret Town-kenya. African Peer Reviewed Journal, 12(1), 555-584.

Katsioloudes, M. I., \& Abouhanian, A. K. (2017). The strategic planning process: Understanding strategy in global markets. London: Routledge Publishers.

Luttmer, E. F. P., \& Singhal, M. (2014). Tax morale. Journal of Economic Perspective, 28(1), 149-168.

Lynch, R. (2015). Strategic management (8th ed.). London: Pearson Publishers.

Manyaka, R. K. (2014). Collection of municipal own revenue in South Africa: challenge and prospects. Journal of Public Administration, 49(1), 127-139. 
Meyer, D. S. (2012). Thinking about strategy. Strategies for Social Change, 1(1), 3-22.

Parnell, J. A. (2014). Strategic management: theory and practice. London: Cengage Learning.

Partidario, M. R. (2012). Strategic environmental assessment: better practice guide. Lisbon: Portuguese Environment Agency and Redes Energéticas Nacionais (REN), SA.

Republic of South Africa. (2017). The National Treasury: Budget Review. Pretoria: Government Printers.

Stewart, C., Carter, C., Kornberger, M., \& Schweitzer, J. (2017). Strategy: Theory and practice. London: Sages Publishers.

Thiga, M. N., \& Muturi, W. (2015). Factors that influence Compliance with tax laws among small and medium sized Enterprises in Kenya. International Journal of Scientific and Research Publications, 5(6), 4-7.

Ungerer, M., Ungerer, G., \& Herhodt. (2015). Crystalising the strategic business landscape. London: KR Publishers.

United States Agency for International Development (USAID). (2013). Leadership in Public Finance. Information Technology for Tax Administration, 7(2), 11-17.

Van De school, R., Lugtig, P., \& Hox, J. (2012). A checklist for testing measurement invariance. European Journal of Development Psychology, 9(1), 486-492.

Weinberg, S. L., \& Abramowitz, S. K. (2016). Statistics using IBM SPSS: an Integrative Approach. London: Cambridge University press.

\section{Copyrights}

Copyright for this article is retained by the author(s), with first publication rights granted to the journal.

This is an open-access article distributed under the terms and conditions of the Creative Commons Attribution license (http://creativecommons.org/licenses/by/4.0/). 